\title{
Day-Ahead Scheduling of a Photovoltaic Plant by the Energy Management of a Storage System
}

Marinelli, Mattia; Sossan, Fabrizio; Isleifsson, Fridrik Rafn; Costanzo, Giuseppe Tommaso; Bindner, Henrik W.

\section{Published in:}

Proceedings of UPEC 2013

Link to article, DOI:

10.1109/UPEC.2013.6715023

Publication date:

2013

Document Version

Early version, also known as pre-print

Link back to DTU Orbit

Citation (APA):

Marinelli, M., Sossan, F., Isleifsson, F. R., Costanzo, G. T., \& Bindner, H. W. (2013). Day-Ahead Scheduling of a Photovoltaic Plant by the Energy Management of a Storage System. In Proceedings of UPEC 2013 IEEE. https://doi.org/10.1109/UPEC.2013.6715023

\section{General rights}

Copyright and moral rights for the publications made accessible in the public portal are retained by the authors and/or other copyright owners and it is a condition of accessing publications that users recognise and abide by the legal requirements associated with these rights.

- Users may download and print one copy of any publication from the public portal for the purpose of private study or research.

- You may not further distribute the material or use it for any profit-making activity or commercial gain

- You may freely distribute the URL identifying the publication in the public portal 


\title{
Day-Ahead Scheduling of a Photovoltaic Plant by the Energy Management of a Storage System
}

\author{
Mattia Marinelli, Fabrizio Sossan, Fridrik Rafn Isleifsson, Giuseppe Tommaso Costanzo, Henrik Bindner \\ Center for Electric Power and Energy \\ Technical University of Denmark, Ris $\emptyset$ Campus \\ Roskilde, Denmark \\ \{matm; faso; fris; guco; hwbi $\} @$ elektro.dtu.dk
}

\begin{abstract}
The paper discusses and describes a system for energy management of a $10 \mathrm{~kW}$ PV plant coupled with a $15 \mathrm{~kW}$ - $190 \mathrm{kWh}$ storage system. The overall idea is, by knowing the meteorological forecast for the next $24 \mathrm{~h}$, to dispatch the PV system and to be able to grant the scheduled hourly energy profile by a proper management of the storage. Due to forecast inaccuracies, the energy manager controls the storage in order to ensure that the plan for hourly energy production is respected, minimizing the storage itself usage. The experimental study is carried out in SYSLAB, a distributed power system test facility at DTU Risø Campus and part of PowerLabDK. Both the PV and the storage are connected to the local network and are fully controllable through the SCADA system. The control management and the models are implemented in MatlabSimulink, which can be interfaced with SYSLAB.
\end{abstract}

Index Terms-- Energy Management, Energy Storage, Grid Integration, Photovoltaic Power.

\section{INTRODUCTION}

The development of the electric system, due to the strong increase of the distributed and renewable generation, is posing new challenges to the management and control of the power system [1]. Concerning the photovoltaic generation, the total installed capacity in Europe, by the end of 2012, is estimated around $69 \mathrm{GW}$, equal to $7 \%$ of the overall electric generation capacity, and moreover this asset will be steadily growing in the next years [2].

From the energy perspective the incidence on the European consumption is lighter, due to the lower capacity factor of this source, compared to the conventional generations; nevertheless, in some Countries like Germany and Italy, the energy covered by the PV is around 7\% and 6\% [3]. However, major issues are related to the PV production profile, which is hardly predictable and manageable [4]. Due to the fact that the conventional power plants are displaced and thus eventually shut down, PV plants will be required, within time, to provide a predictable production plan and to be able to grant it, even if the meteorological conditions differ from the forecasted ones. Having the PV plants properly dispatched allows the network operators to better manage the other producing sources. Respecting the forecasted production profile is essential in order to have the power system working properly.

The paper develops as follows: the problem outlines are presented in the Paragraph II along with description of the model layout and the proposed control strategy. Paragraph III describes the simulation results obtained in the different test scenarios with several power sizes of the storage system. The conclusions and the future developments are presented in Paragraph IV. The Reference Paragraph closes the paper.

\section{MODEL DESCRIPTION}

\section{A. Problem Outlines}

The day-ahead, an hourly energy production plan for the PV system is defined. This plan is calculated by knowing the PV module layout information and the weather forecasts. The hourly production plan must be respected within $\pm 1 \%$. Deviations are mainly due to forecast errors and eventually imprecisions in the model parameters. The storage system can be used to correct the deviations from the plan, but it is very crucial not to overuse it, because any charge/discharge cycle would lead to energy losses. For example, it has to be kept in mind that, during windy and cloudy days, there could be an excess of production in the first half an hour, followed by a lack of production in the second half. In this case the good management strategy would foresee the use of the battery just in the last minutes, avoiding a depleting charge in the first half, followed by a discharge in the second half. On the other hand the control action cannot be taken too late otherwise the power size of the battery could limit the provision of energy in order to compensate the scheduling error.

\section{B. System layout}

The conceptual model of the system is illustrated in Fig. 1. The $10 \mathrm{~kW}$ PV plant, composed by a $5 \mathrm{~kW}$ thin film module (Copper Indium Selenium) section and a $5 \mathrm{~kW}$ polycrystalline modules section, is interfaced to the low voltage $400 \mathrm{~V}$ network via a 3 phases inverter. The thin film part is formed by 84 modules $60 \mathrm{~W}$ nominal power $(-2 \% /+8 \%$ tolerance $)$ divided in 6 parallel strings of 14 modules. The crystalline section is formed by 1 string of 22 modules $230 \mathrm{~W}$ nominal power $(0 /+3 \%)$. The storage is modelled according to the Vanadium Redox Flow Battery installed in the SYSLAB and is formed by a series of 3 stacks composed by 42 cells each and equipped with two tanks containing 6,500 litres of Vanadium solution each leading to a theoretical storing capacity of $320 \mathrm{kWh}$, limited by the Battery Management System (BMS) to $190 \mathrm{kWh}$. The storage is equipped with an 
inverter capable of providing up to $\pm 15 \mathrm{~kW}$ and $\pm 12 \mathrm{kVAr}$ and it is able to ramp from full power charge to full power discharge within few seconds. For the study purpose it is interesting to analyse which is the optimal size of the battery converter related to the size of the PV plant, therefore the battery inverter will be limited in the output, depending on the scenario analysed. The storage system is connected in parallel to the PV plant and the overall system is connected with a cable to the local LV main network. At the Point of Common Coupling (PCC) the power transit is measured and integrated over the time in order to calculate the cumulated energy within the hour, this value is sent to the control system, realized in Matlab-Simulink, and compared with the energy schedule evaluated by the photovoltaic model.

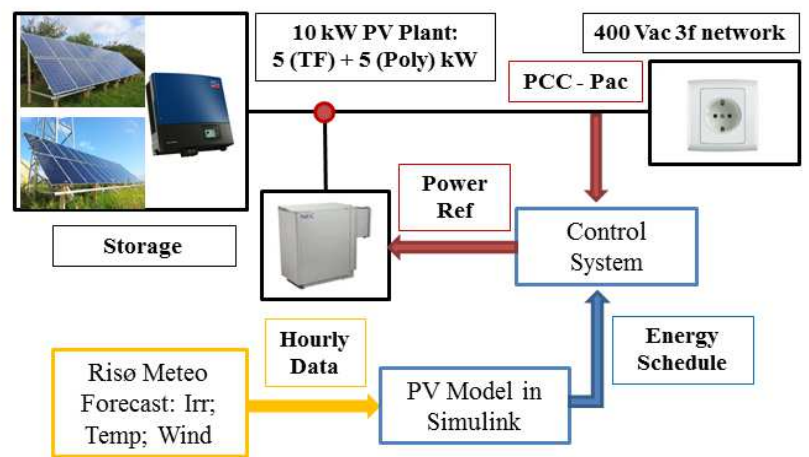

Fig. 1. Conceptual Model.

The meteorological forecast service, provided by the DTU Wind Energy Department, gives the forecasted data input on hourly basis used to evaluate the predicted PV output: the horizontal irradiance, the air temperature and the wind speed at 2 meters above the ground [5]. The Simulink PV model, realized in Simulink and reported Fig. 2, is formed by several blocks, where the equation for the description on the movement of the Sun and the evaluation of the efficiency chain in the energy conversion process of the PV module, starting from the Sunlight getting to the AC output, are implemented [6], [7].

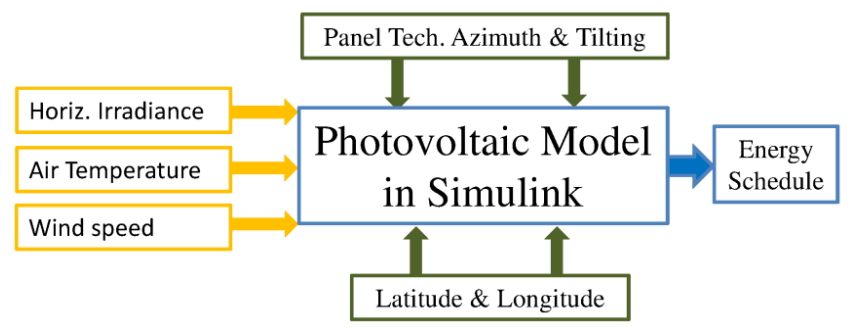

Fig. 2. PV Model block diagram concept.

The panel model has been characterized in accordance with the data provided by the manufacturers and considering the experience acquired from the PV installed in the SYSLAB laboratory of the DTU Ris $\emptyset$ Campus. The DC power produced by the module mainly depends on the incident solar radiation and on the temperature, which for instance is function of air temperature, wind speed and radiation itself. The dependence of the panel output with different sunlight intensity and the dependence in function of the temperature have been evaluated in order to evaluate the reduction from the nominal efficiency, having taken in account that the nominal data are provided for standard meteorological conditions $\left(1000 \mathrm{~W} / \mathrm{m}^{2}\right.$ and $\left.25{ }^{\circ} \mathrm{C}\right)$. The comparison between the historical production for the studied day and the output with the model is reported in Fig. 3. The first plot shows the data with 1 minute sample, while the second one reports the hourly averages.
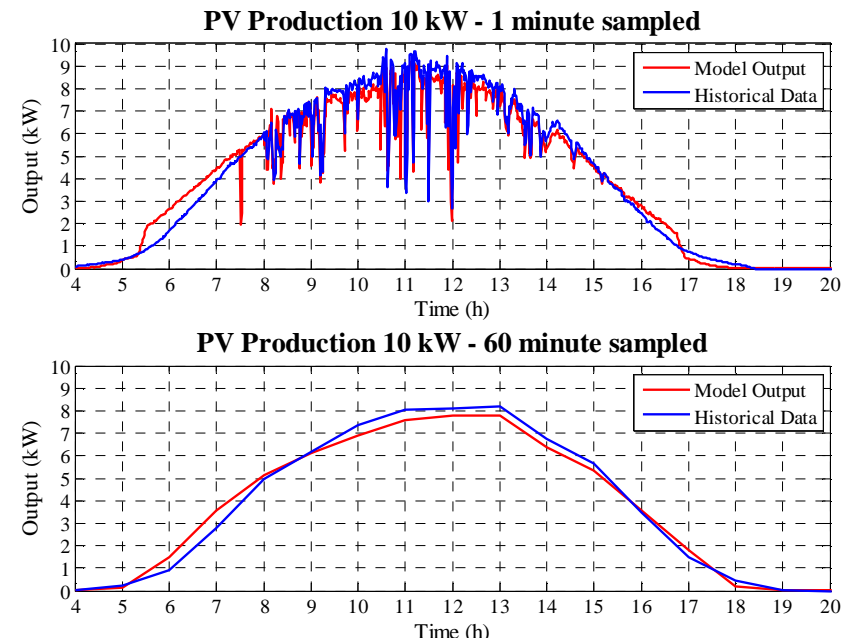

Fig. 3. PV model output and historical data for the studied day: 04 May 2013 reported with different time sample (1 minute and 60 minutes). The measurements are referred to the AC side.

\section{Energy Management Strategy}

The management strategy operates within each hourly time frame. The input of the controller is the power measured at the PCC, which is not directly used in the control loop; but it is used to compute the correspondent energy reference within the hour. This reference is compared with the energy profile that should be followed for achieving the hourly energy target, identified by the blue line of Fig. 4 .

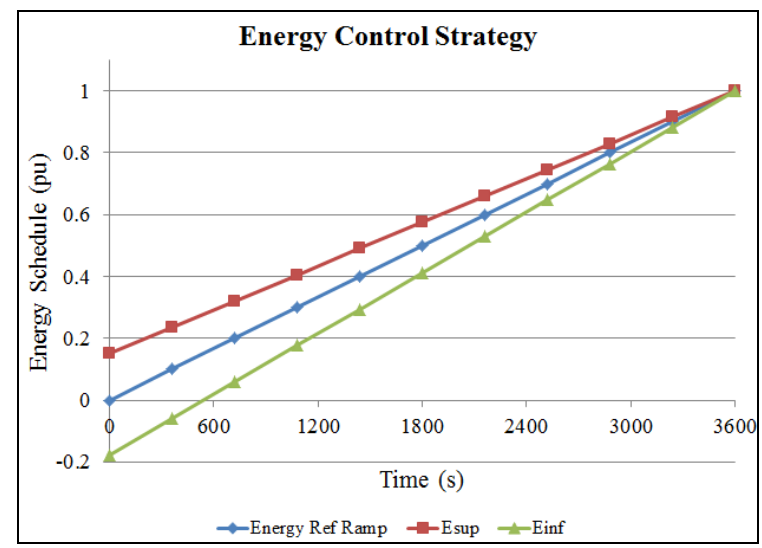

Fig. 4. Energy Management Strategy. Reference energy in blue. Lower band in green and upper band in red. 
The red and the green lines form the control band: whenever the energy profile exceeds the upper or the lower bound (red and green line of Fig. 4) the battery is activated: the more the distance from the objective value, the deeper the charge/discharge required. On the contrary, if the produced energy matches the scheduled one, or it is inside the band, no charge/discharge actions are performed.

This kind of control strategy has been successfully used and described in a previous work, that was aimed at controlling a renewable generation set composed by an 11 $\mathrm{kW}$ wind turbine and a vanadium based storage system [8].

\section{Energy Control Management Strategy tailored to the PV}

The energy management strategy presented in Fig. 4 is suitable if the predicted power generation (or consumption in case of demand side management) is expected to be constant within the hour, which is not the case for a PV system. The hourly control strategy has therefore to be adapted to the typical production pattern of a PV system and its amplitude and shape is going to change according to the hour of the day as well as according to the day of the year and on the specificity of the plan layout: tilting and azimuth of the modules, geographical position, mutual shadows in case of multiple arrays.
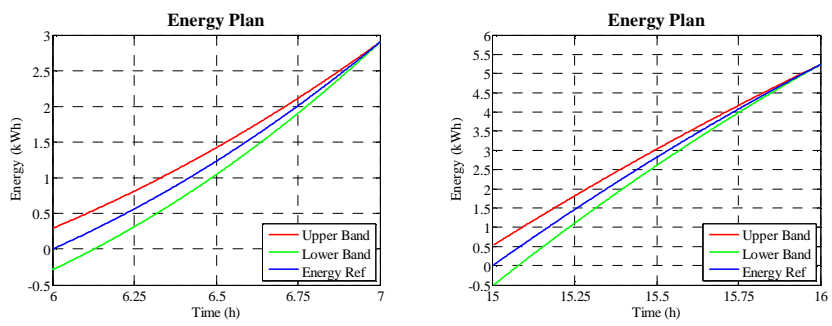

Fig. 5. Energy Control Strategy for the PV plant localized in Roskilde (DK) on the $4^{\text {th }}$ May for 6-7 am (left plot) and 3-4 pm (right plot). Time in GMT.

It is interesting to observe that the curves are concave up during the morning hours while the concavity is going to change during the day. The energy plan will be composed by almost straight lines around noon. The curves will be concave down during the afternoon. The reason behind this behavior is due to the fact that power output of a PV plant during sunny days is going to increase during the morning, reaches the maximum and remains stable in the noon and starts decreasing during the afternoon. Since the curves forming the energy plan are depending on the integral function of the power output, the different power level during the day and during the hour is reflected in the shape of the energy control strategy lines.

The opening of the lines, that means the distance between the upper and lower band referred to the energy ref line, will determine the stiffness of the control. In this case the initial opening is $\pm 10 \%$ of the final energy value and it is progressively reduced within the hourly control window in order to guide the energy production of the plant. Whenever the energy state of the system reaches the band, the storage is activated in order to compensate the error. The sensitivity of the controller is chosen in order to have the storage to store/release the maximum power if the energy error is equal or greater to $1 \%$. If the error is within $1 \%$ and $0 \%$, the battery power set-point is changed by five discrete steps $20 \%$ amplitude.

\section{Simulation ResUlts}

\section{A. Simulation Procedure}

The simulation day chosen is the $4^{\text {th }}$ May 2013, which was a sunny day with frequent clouds passages. The simulation process is here explained:

- The forecast meteorological data (solar irradiation, wind speed, air temperature) of the studied day are used to evaluate the PV output. The day-ahead forecasts that mean the forecasts given at the 8 am of the $3^{\text {rd }}$ May 2013 are taken in consideration.

- The PV model output is used to build the energy plan for the studied day ( $4^{\text {th }}$ May), shown in Fig. 6.

- Since a sensitivity analysis aimed at finding the suitable size of the storage system, several simulations are run using the historical production data of the PV installed in the SYSLAB and using the Simulink model of the storage. The storage model used is described in [9].

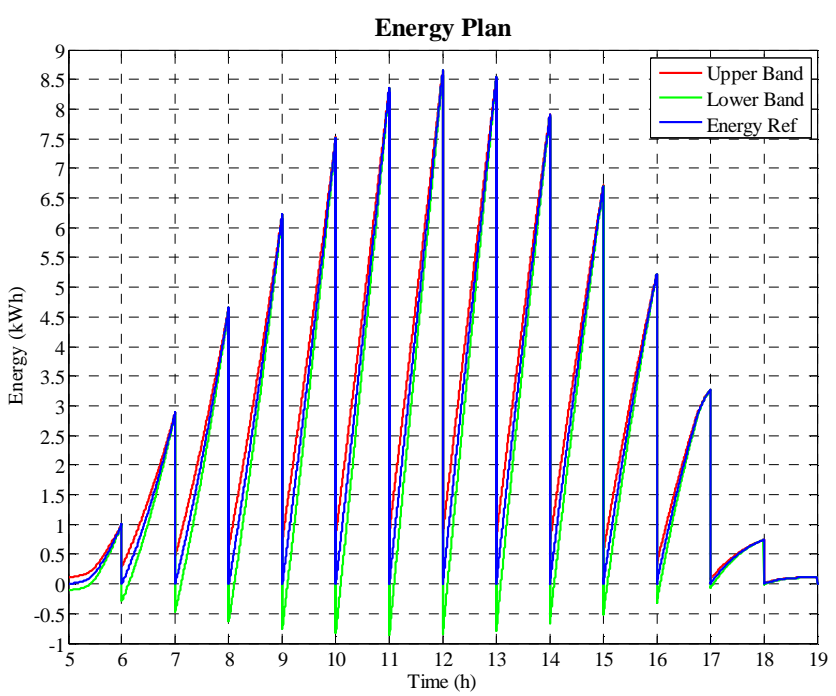

Fig. 6. Energy plan for the 04 May 2013. Time in GMT.

A preliminary comparison between the forecasted PV production with the historical data is shown in Fig. 7. The historical production data have been hourly averaged, while the forecast production is already hourly averaged since the forecast data maximum detail is 1 hour. It can be seen that the forecasts are overestimating the solar production in the afternoon. The total energy produced by the PV for the studied day was $64.6 \mathrm{kWh}$, while, according to the forecasts, it would be $71.8 \mathrm{kWh}(+11 \%)$. The forecasted hourly production will be the plan that the energy manager of the plant is going to propose in the market and is assumed to be respected every hour with an average hourly error of less than 
$1 \%$ during the day and a $3 \%$ maximum error. Therefore there is the need to decide the optimal size of the storage that has to be coupled to the PV plant in order to compensate the unavoidable forecasts error.

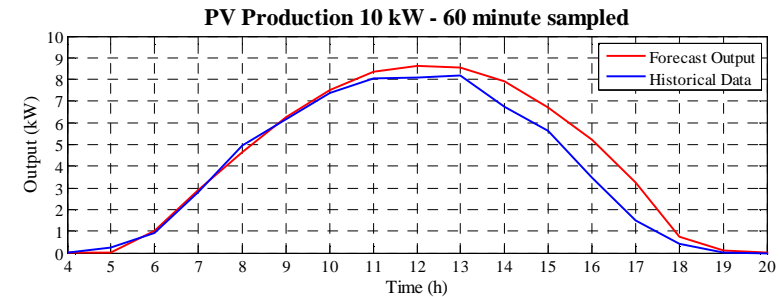

Fig. 7. Comparison between the forecasted PV production and the historical 1 hour average data.

\section{B. Scenario Base - no storage}

In this scenario the base case is reported: it presents the situation where no storage is installed. Fig. 8 shows the hourly energy produced by the system (in this case composed by the PV plant alone) and the errors made due to the forecast errors. The relative average error is equal to $17.3 \%$ and the maximum one is greater than $50 \%$. The most significant data are summarized in Table I along with the other simulations results. The same results can be observed from Fig. 9 which shows the cumulated energy within each hour (black line) and the predicted energy plan. The energy state fails to reach the target value at the end of the afternoon hours.
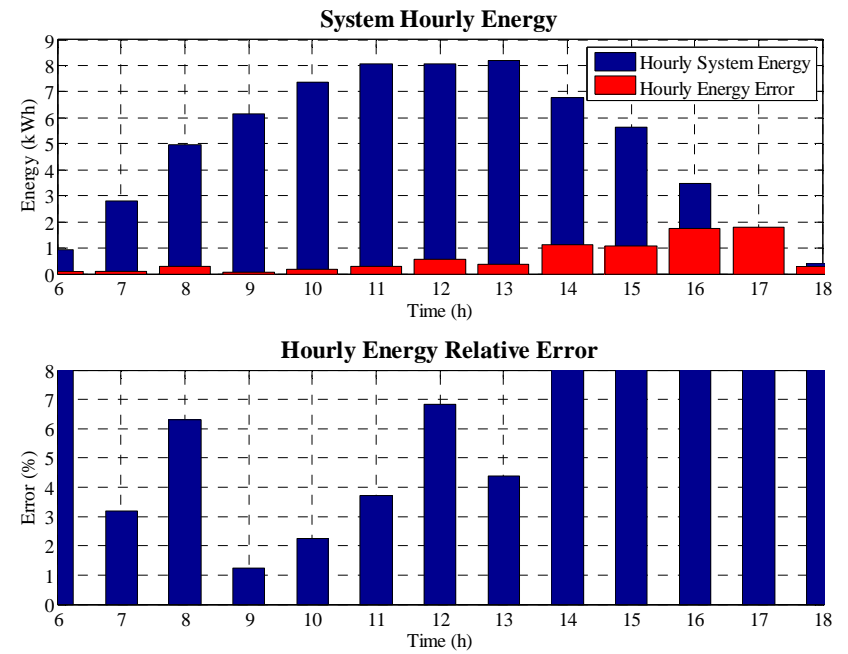

Fig. 8. System hourly energy and hourly energy error, absolute and relative.

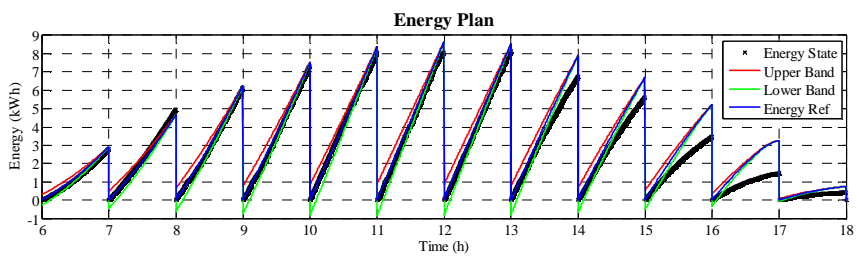

Fig. 9. System energy production and expected energy plan. No storage.

\section{Scenarios with different storage power size}

In this section the results with different storage power sizes are reported. The improvements of the system performance are showed. The system performances indicators are reported in the final table I.

The cumulated energy and the storage production with a proposed storage size of $10 \%$ of the nominal PV size that means $1 \mathrm{~kW}$ is shown in Fig. 10. A detail for the time period between 6 and 7 in the morning is illustrated in Fig. 11. It is possible to appreciate the action of the storage and how it is able to take the system energy production within the desired band.
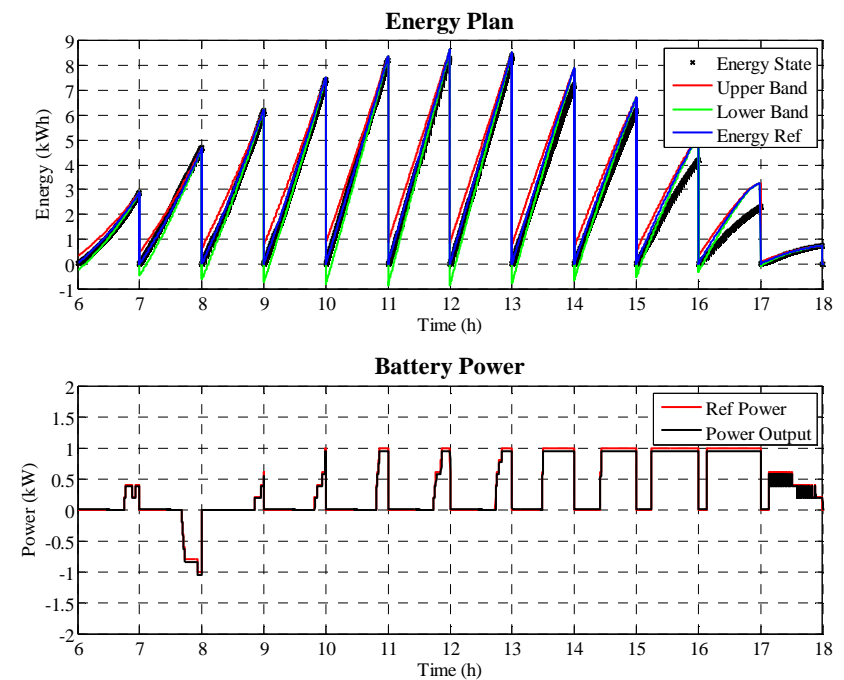

Fig. 10. System energy production and expected energy plan. Storage size $10 \% \mathrm{PV}$ power $(=1 \mathrm{~kW})$.
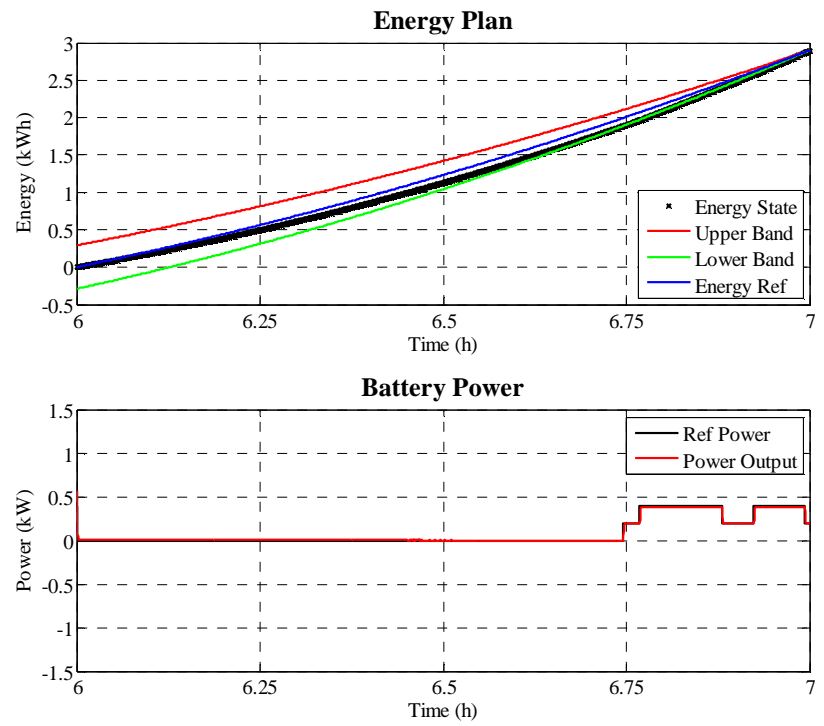

Fig. 11. Detail between 6-7 am of the system energy production and expected energy plan. The storage production is reported in the second plot. Storage size $10 \% \mathrm{PV}$ power $(=1 \mathrm{~kW})$. 
In Fig. 12 it can be seen instead that the lack of PV production is too large for the storage limited size to be compensated and therefore the target level of energy cannot be reached.
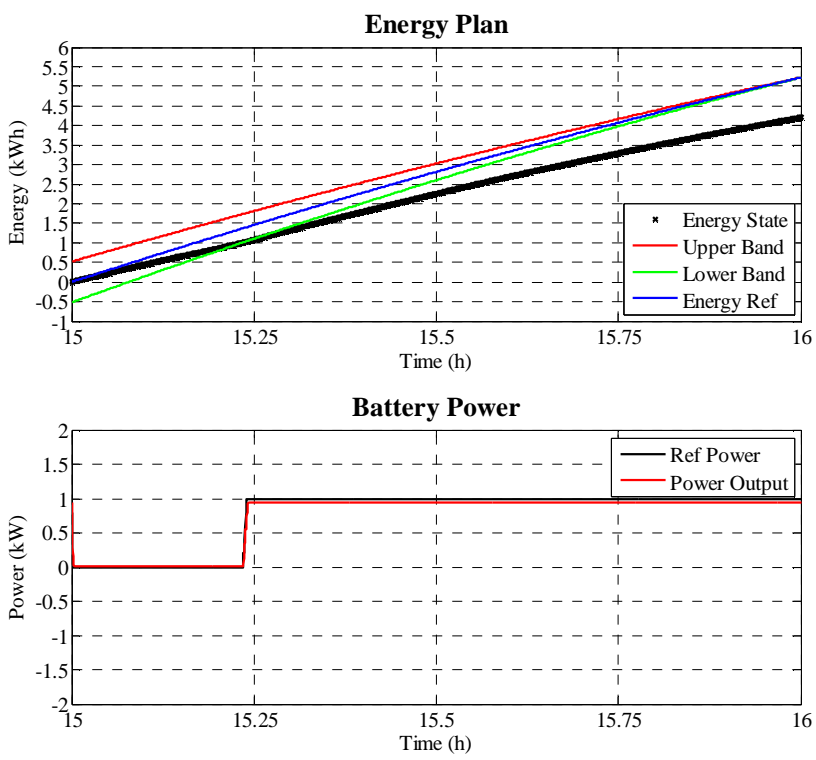

Fig. 12. Detail between 3-4 pm of the system energy production and expected energy plan. The storage production is reported in the second plot. Storage size $10 \% \mathrm{PV}$ power $(=1 \mathrm{~kW})$.

Fig. 13 shows the same time interval with the storage power increased to $20 \%$ of the PV size (that means $2 \mathrm{~kW}$ ). The performances are improved.
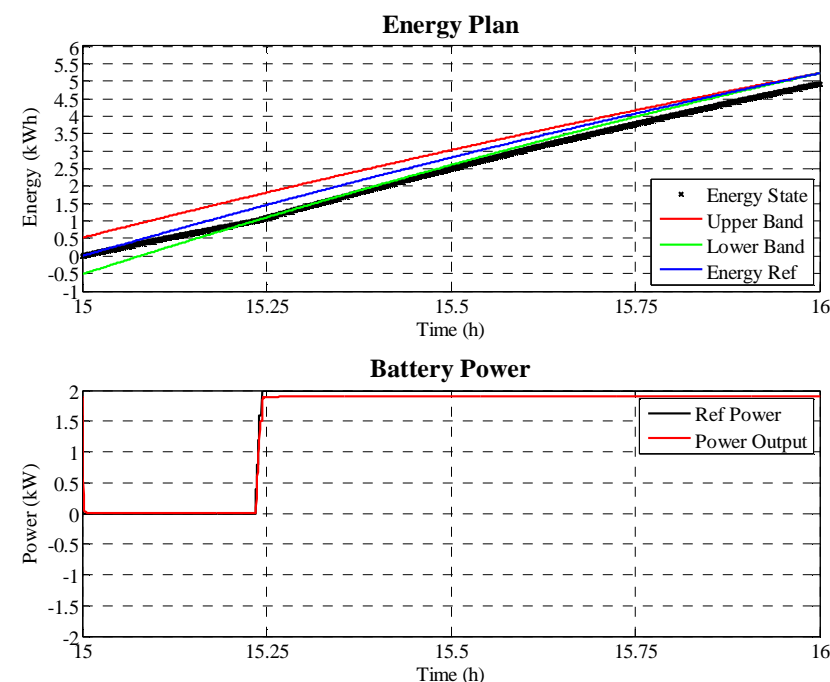

Fig. 13. Detail between 3-4 pm of the system energy production and expected energy plan. The storage production is reported in the second plot. Storage size $20 \% \mathrm{PV}$ power $(=2 \mathrm{~kW})$.

The following simulations graphs (Fig. 14, Fig. 15 and Fig. 16) are obtained with a storage size of $3 \mathrm{~kW}$ (30\% scenario), which is the optimal scenario. Further increases of the storage power size do not lead to valuable improvements.
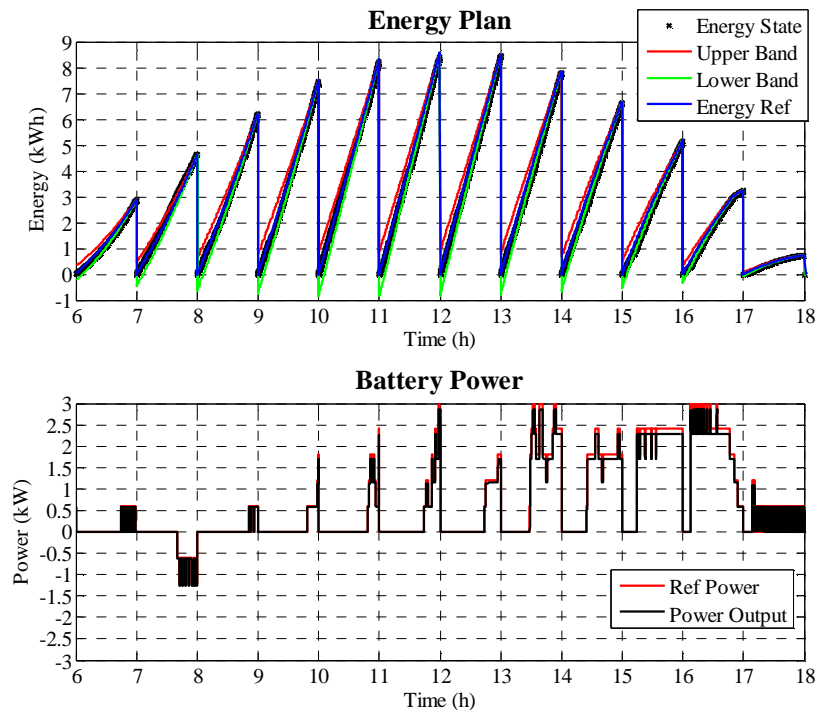

Fig. 14. System energy production and expected energy plan. Storage size $30 \% \mathrm{PV}$ power $(=3 \mathrm{~kW})$.
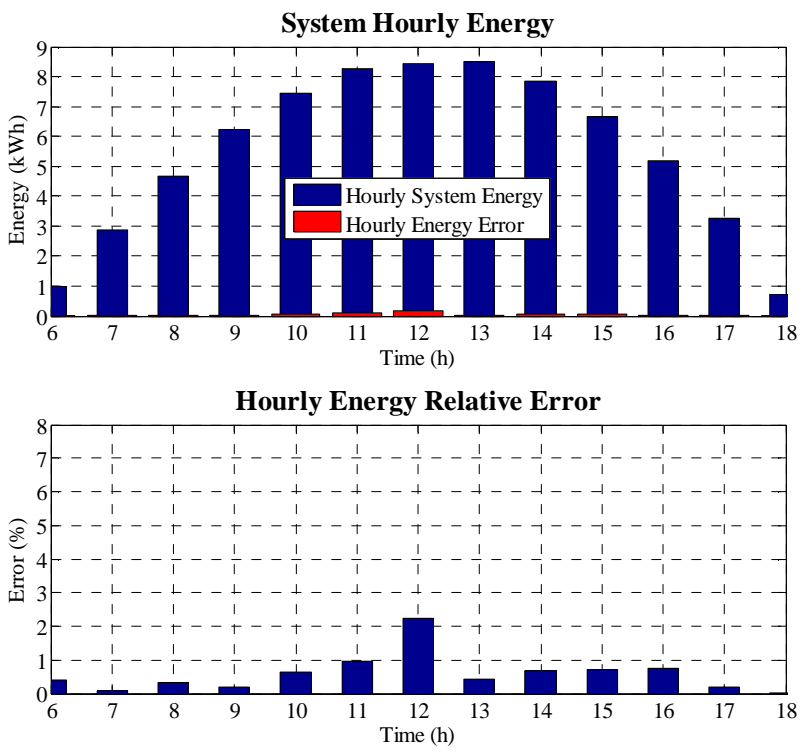

Fig. 15. System hourly energy and hourly energy error, absolute and relative. Storage size $30 \% \mathrm{PV}$ power $(=3 \mathrm{~kW})$.

It is interesting to observe in Fig. 16 the behavior of the power measure at the PCC (first plot) which for certain aspects is worsen because of the power steps which can be induced by the storage operation. However it has to be kept in mind that the objective of the control strategy proposed is driven from an energy perspective due to the need to respect the scheduled energy plan the day-ahead.

The Table I provides an overview of the results obtained with different storages with a power spanning from $5 \%$ to $50 \%$. The most important indicators reported are the battery usage, that means the summation of the energy flow in and out the battery regardless the sign and the released (or stored if negative) energy at the end of the day. The average and the maximum errors are also reported. As it can be seen, a 
storage size greater than $30 \%$ does not lead to valuable improvements.
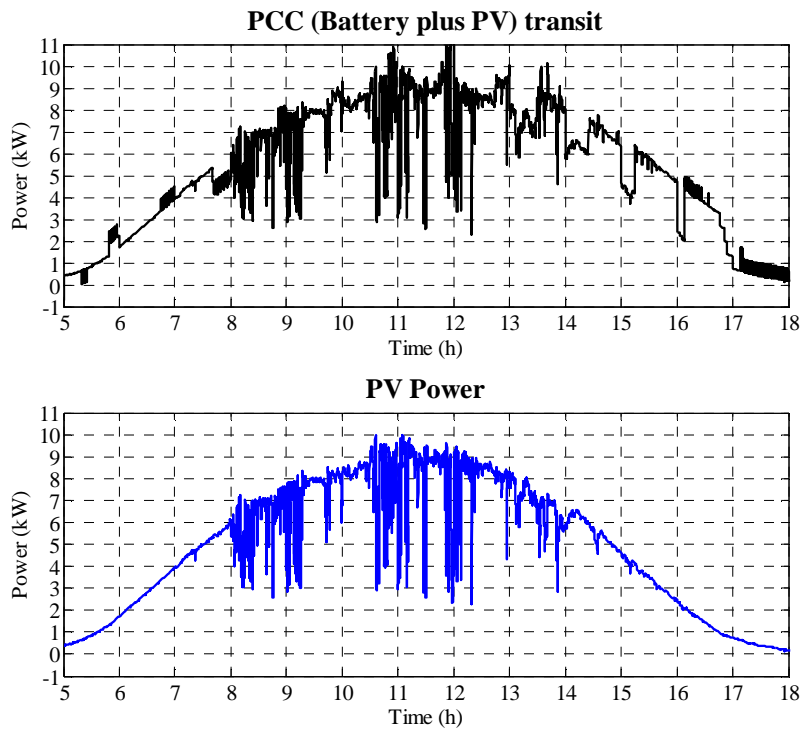

Fig. 16. PCC transit and PV power production. Second sampled values.

TABLE I

STORAGE USAGE AND SYSTEM PERFORMANCES

\begin{tabular}{|c|r|r|r|r|}
\hline & \multicolumn{1}{|c|}{$\begin{array}{c}\text { Storage } \\
\text { usage }(\mathrm{kWh})\end{array}$} & \multicolumn{1}{c|}{$\begin{array}{c}\text { Energy } \\
\text { released } \\
(\mathrm{kWh})\end{array}$} & $\begin{array}{c}\text { Average } \\
\text { hourly error }\end{array}$ & $\begin{array}{c}\text { Max } \\
\text { hourly error }\end{array}$ \\
\hline $\begin{array}{c}\text { Base case } \\
\text { size 0\% PV }\end{array}$ & 0 & 0 & $17.3 \%$ & $>50.0 \%$ \\
\hline $\begin{array}{c}\text { Storage } \\
\text { size 5\% }\end{array}$ & 2.64 & 1.90 & $10.3 \%$ & $>50.0 \%$ \\
\hline $\begin{array}{c}\text { Storage } \\
\text { size 10\% }\end{array}$ & 4.45 & 3.54 & $7.2 \%$ & $41.2 \%$ \\
\hline $\begin{array}{c}\text { Storage } \\
\text { size 15\% }\end{array}$ & 6.03 & 5.07 & $4.1 \%$ & $19.8 \%$ \\
\hline $\begin{array}{c}\text { Storage } \\
\text { size 20\% }\end{array}$ & 7.43 & 6.46 & $1.5 \%$ & $6.1 \%$ \\
\hline $\begin{array}{c}\text { Storage } \\
\text { size 25\% }\end{array}$ & 7.99 & 6.99 & $0.7 \%$ & $2.6 \%$ \\
\hline $\begin{array}{c}\text { Storage } \\
\text { size 30\% }\end{array}$ & 8.10 & 7.10 & $0.6 \%$ & $2.2 \%$ \\
\hline $\begin{array}{c}\text { Storage } \\
\text { size 50\% }\end{array}$ & 8.28 & 7.27 & $0.5 \%$ & $1.4 \%$ \\
\hline
\end{tabular}

\section{CONCLUSIONS AND FUTURE DEVELOPMENTS}

The proposed paper aims at describing a system for energy management of a $10 \mathrm{~kW}$ PV plant coupled with a $15 \mathrm{~kW}$ $190 \mathrm{kWh}$ storage system. The overall idea is, by knowing the meteorological forecast for the next $24 \mathrm{~h}$, to dispatch the PV system and to be able to grant the scheduled hourly energy profile by a proper management of the storage. Due to forecast inaccuracies, the energy manager controlled the storage in a predefined way in order to ensure that the hourly energy production plan is respected, minimizing the storage itself usage.

The study is in the early stage and is intended to describe the methodology, to evaluate the size of the coupled storage system and to define the way of managing it in order to respect the proposed day-ahead energy schedule.
Further analysis will be aimed at extending the study along the whole year and at evaluating the behaviour of the energy manager in case of different forecast horizons. Subsequently experimental tests will be run in the test facility using the energy controller model in the loop with the PV plant and the Vanadium Battery, properly limited in its power output.

\section{REFERENCES}

[1] R. J. Thomas, "Putting an action plan in place," IEEE Power Energy Mag., vol. 7, no. 4, pp. 26-31, Jul./Aug. 2009.

[2] Connecting the Sun - Solar Photovoltaics on the Road to Large Scale Grid Integration, EPIA - European Photovoltaic Industry Association, Brussels, BE, Sep 2012. [Online].Available: http://www.epia.org/news/publications/connecting-the-sun/

[3] J.V. Appen, M. Braun, T. Stetz, K. Diwold, D. Geibel, "Time in the Sun: The Challenge of High PV Penetration in the German Electric Grid," Power and Energy Magazine, IEEE, vol.11, no.2, pp.55,64, March 2013

[4] K.F. Katiraei, J.R. Agüero, "Solar PV Integration Challenges," Power and Energy Magazine, IEEE, vol.9, no.3, pp.62-71, May-June 2011.

[5] A. N. Hahmann, D. Rostkier-Edelstein, T. T. Warner, F. Vandenberghe, Y. Liu, R. Babarsky, S. P. Swerdlin, "A reanalysis system for the generation of mesoscale climatographies," Journal of Applied Meteorology and Climatology, Vol. 49, No 5, 2010, pages 954-972.

[6] E. Skoplaki, A.G. Boudouvis, J.A. Palyvos, "A simple correlation for the operating temperature of photovoltaic modules of arbitrary mounting", Solar Energy Materials and Solar Cells, Vol. 92, Issue 11, November 2008, pages 1393-1402, ISSN 0927-0248, 10.1016/j.solmat.2008.05.016.

[7] C. Koch-Ciobotaru, L. Mihet-Popa, F. R. Isleifsson, H. Bindner, "Simulation model developed for a small-scale PV system in distribution networks," Applied Computational Intelligence and Informatics (SACI), 2012 7th IEEE International Symposium on, pp.341-346.

[8] F. Baccino, M. Marinelli, F. Silvestro, O. M. F. Camacho, F. R. Isleifsson and P. Norgard, "Experimental validation of control strategies for a microgrid test facility including a storage system and renewable generation sets," Integration of Renewables into the Distribution Grid, CIRED 2012 Workshop, pp.1-4.

[9] F. Baccino, S. Grillo, M. Marinelli, S. Massucco, F. Silvestro, "Power and Energy Control Strategies for a Vanadium Redox Flow Battery and Wind Farm Combined System", IEEE ISGT 2011, pp. 1-8, Manchester, 5-7 Dec. 2011. 